\title{
Da dialética do reconhecimento em Hegel à dialética do trabalho e teoria da emancipação em Marx. ${ }^{1}$
}

Newton Pereira Amusquivar Junior ${ }^{2}$

Resumo: nesse texto analisarei o diálogo entre Hegel e Marx num aspecto central para a compreensão do segundo: o trabalho. O debate em relação ao tema do trabalho está interligado com a posição de Hegel na dialética do reconhecimento e como Marx por um lado absorve e por outro lado critica o mesmo filósofo nesse ponto teórico, chegando nisso a uma base para sua teoria da emancipação.

Palavras-chave: trabalho, alienação, estranhamento, consciência.

Abstract: It is undeniably a dialogue between Hegel and Marx, as in their convergences or divergences. In this text I analyze the dialogue between them aiming to a central subject for the comprehension of Marx's theory: the work. The debate on the subject of work is connected with Hegel's point of view about the recognition dialectics and how Marx, on one hand, absorbs it, and on the other hand, criticize Hegel about this subject, reaching through this a basis for his theory of emancipation.

Keywords: work, alienation, estrangement, consciousness.

${ }^{1}$ Artigo inspirado na conclusão de uma pesquisa de iniciação cientifica realizando de 2007 a 2008 e financiado pela FAPESP.

${ }^{2}$ Graduando em filosofia mo Instituto de Filosofia e Ciências Humanas (IFCH) da UNICAMP. Endereço eletrônico: newtonpa@ig.com.br 
O objetivo desse artigo é evidenciar a articulação presente entre a dialética do reconhecimento de Hegel com a noção de trabalho e emancipação presente nos Manuscritos de 1844 de Marx. Pretende-se assim destacar as heranças de Marx em relação ao idealismo alemão, ao mesmo tempo em que destacaremos como Marx absorve essa herança com uma crítica materialista já presente nesse período. Para realizarmos isso partiremos da analise da dialética do reconhecimento de Hegel na Fenomenologia do Espírito e Filosofia do Direito, para depois analisar como esses conceitos reaparecem os Manuscritos de 1944 de Marx.

A dialética do reconhecimento surge em Hegel no desenvolvimento da consciência-de-si, que é uma reflexão de si a partir do outro, ou melhor, é um retorno a si mesmo pelo mundo sensível. No desenvolvimento inicial da consciência-de-si esse ser sensível é marcado com um caráter negativo, ou seja, a consciência-de-si tende a negar esse ser para afirmar a sua identidade consigo mesmo. O desejo é o que expressa melhor esse movimento inicial da consciência-de-si, pois ele reconhece o ser-outro sensível, mas não respeita esse ser-outro. $\mathrm{O}$ desejo quer negar a sua alteridade sensível ao se apropriar concretamente desse objeto sensível numa negação pela qual a consciência afirma a si mesma. Entretanto, o que a consciência-de-si como desejo não percebe é que o seu objeto é tão independente como ela mesma, pois seu objeto não é apenas um objeto sensível qualquer (particular), mas o objeto sensível é mais universal: a vida. A vida não é um ser sensível imóvel, mas é um devir circular tal como a consciência-de-si, e nisso a vida é tão independente como o próprio desejo. Nos seres vivos, o desejo é negação unilateral desse objeto independente (vida) através do consumo, mas na satisfação desse consumo a consciência realiza, sem saber, a experiência da independência desse objeto que ela tenta destruir. Assim, o desejo alcança a sua certeza de si mesmo, mas tanto o desejo como a certeza de si mesmo são condicionados pela vida que fica como objeto independente, pois sem a vida o desejo se desintegra. O desejo consegue apenas uma negação de seu objeto, não conseguindo ter domínio sobre ele, uma vez que ele não nega dialeticamente a coisa (negação que ocorrerá apenas com o trabalho, tal como mostraremos mais adiante). 
O desejo se torna então escravo da vida. Assim, a experiência dessa consciência-de-si é inadequada para assegurar a sua certeza de si como verdade. $\mathrm{O}$ objeto de desejo (a vida) é incapaz de realizar a mediação para que a consciência-de-si realize o seu retorno dialético a si, pois a vida é um infinito que dissolve as suas diferenças em si mesmo, o desejo realiza um movimento no qual o objeto é consumido e logo depois surge outro objeto independente para o desejo consumir novamente, ficando nisso num mau infinito.

Para realizar essa identidade concreta de si, o desejo da consciência-de-si não deve se referir a um objeto sensível dado independente pela vida, mas o desejo deve se referir a outro objeto além desse aí dado, trata-se de uma outra consciência-de-si. Logo, o desejo vai desejar um outro desejo passando o desejo do reino animal (natural e mecânico) para o reino humano (fins éticos e teleológico). Esse reino humano é estritamente um reino social, pois "a consciência-de-si só alcança sua satisfação em uma outra consciência-de-si" (HEGEL, 2007, p.142). Nisso a consciência-de-si só deixa de ser condicionada pela vida na medida em que ela é social, pois quando ela se relaciona com uma outra consciência-de-si, então se abre a possibilidade de ir para além da natureza. Agora o desejo não quer mais algo particular e nem a vida, mas sim uma outra consciência-de-si. Nisso se inicia a dialética do reconhecimento, na qual há uma busca por si como fim em si mesmo. No fundo é essa busca que está presente na consciência, pois ela visa deixar o mundo sensível determinado e chegar ao mundo ético, em que, com as ações teleológicas, seria possível a liberdade.

De imediato o reconhecimento não é mútuo e igual, no qual cada consciência-de-si reconhece a si mesmo na outra e agem sobre si mutuamente, esse seria o conceito abstrato do reconhecimento pelo qual Hegel começa na Fenomenologia apenas na exposição para apontar onde deve chegar o reconhecimento no concreto. Com isso, o reconhecimento na efetividade imediata não será recíproco e igual, mas unilateral e desigual. Por que de início se tem a desigualdade? Isso ocorre pelo fato da consciência-de-si estar ainda ligada e dependente ao sensível. A consciência-de-si ainda não realizou "o movimento da abstração 
absoluta, que consiste em extirpar todo ser imediato, para ser apenas o puro ser negativo da consciência igual-a-si-mesma" (HEGEL, 2007, p.145). A consciência-de-si deve abstrair esse ser-imediato dela, ou seja, ela tem que ser independente da vida orgânica, mas aqui ela se encontra ainda dependente do sensível. E nessa dependência a consciência se relaciona com a sua alteridade de maneira absolutamente negativa, a saber, ela afirma apenas a si mesma e nega completamente o seu seroutro.

Assim, o agir inicial de uma consciência-de-si com relação à outra consciência-de-si não será tal como se tem no reconhecimento recíproco que é mútuo e amistoso, pelo contrário, o agir será de pura negação de uma consciência-de-si em relação à outra no qual cada consciência-desi vai querer a morte da outra e arriscar a vida para matar a outra. Nisso fica óbvio qual é a primeira relação entre as duas consciências-de-si: é uma luta de vida ou morte. Nessa luta de vida e morte, a consciênciade-si arrisca a própria vida, não pela vida sensível, mas por seu reconhecimento, trata-se então de uma primeira distancia do sensível e natural, deixando de lado a dependência com a natureza. Nota-se também que aqui a relação imediata será de hostilidade, cada uma quer negar (matar) a outra, mas não será pela morte que teremos o reconhecimento, trata-se apenas do querer da morte que entra na dialética do reconhecimento. Se ocorrer de fato a morte de um dos lados, então não há reconhecimento. A luta entre vida e morte deve ter como resultado não a morte, mas uma relação entre ambos os extremos que será completamente desigual e unilateral: a dialética do senhor e escravo. Aqui os extremos (cada uma das consciências-de-si) são opostos onde um é reconhecido e outro reconhece, uma consciência será o essencial e a outra é tratada como coisa. Os dois extremos são desiguais e opostos: uma consciência é senhor e a outra consciência é escravo. Esse é o silogismo da dominação, no qual é bem relevante notar como a relação de cada consciência com a natureza é mediatizada com a outra consciência pelo trabalho, ou seja, pela produção e auto-produção.

A relação do senhor com a natureza vai ser mediatizada pelo escravo, assim a consciência-de-si do senhor não será mais o simples

64 Da dialética do reconhecimento em Hegel à dialética do trabalho... 
consumo do desejo sensível imediato com a vida, mas agora há a mediação com um outro (escravo). O senhor não busca o seu objeto de desejo na natureza, mas é pelo escravo que esse objeto de desejo aparece. Esse escravo também não é apenas um animal domesticado, mas é um ser humano, em suma um animal que busca ser reconhecido e é dominado apenas porque está preso na vida, pois preferiu viver como escravo no lugar da morte, assim teve a experiência que leva à sabedoria do medo da morte, logo também a relação do senhor com o escravo é mediado pela a natureza.

Através da mediação do trabalho do escravo o desejo do senhor não está dependente da natureza, pois o senhor goza absolutamente sem se tornar dependente do objeto consumido. Assim, o senhor "consegue o que o desejo não conseguia: acabar com a coisa, e aquietarse no gozo" (HEGEL, 2007, p.148). Isso ocorre pelo fato do escravo trabalhar e transformar a natureza, logo a natureza não se mostra mais independente e o desejo dependente, como ocorria na dialética do desejo, mas agora a vida - na medida em que o seu lado independente fica para o escravo - se torna dependente e o desejo independente.

Nesses dois momentos o senhor se mostra como ser essencial (Serreconhecido) e o escravo como inessencial. Aqui não temos o agir de um que ao mesmo tempo é o agir de outro, ou seja, não temos um agir mútuo, mas um agir desigual. Com isso, não temos uma independência verdadeira no senhor, pois a independência verdadeira ocorre por um reconhecimento recíproco. A independência do senhor é uma contradição na medida em que no seu reconhecimento ele é reconhecido por um ser que não é essencial (escravo) e o seu agir é um agir do escravo, ou seja, é também um agir inessencial.

Já do lado do escravo percebemos que a essência não está em si, tal como ocorria com o senhor, estando a essência no outro (no senhor). O escravo sentiu a negatividade de si mesmo pela angústia, pois na luta sentiu o medo da morte. Assim, diante da morte o escravo tremeu inteiramente e tudo o que era fixo vacilou, pois diante de si o escravo notou a sua finitude, alcançando nisso uma sabedoria humana e não animal: a consciência da sua morte. Entretanto, o escravo não pode ficar 
apenas nesse sentimento de angústia, é necessária a efetivação que ocorre no servir e trabalhar. De fato o escravo está preso na vida (o medo da morte o colocou na escravidão), mas é só na cadeia da vida que o escravo encontra a possibilidade de se libertar mediante o trabalho. Enquanto no desejo do senhor temos um consumo imediato que é puro desaparecer sem um lado objetivo que subsiste, no escravo há uma coisa completamente diferente, pois ele não consome imediatamente, pelo contrário, o escravo trabalha, e "o trabalho (...) é desejo refreado, um desvanecer contido, ou seja, o trabalho forma" (HEGEL, 2007, p.150). O medo da morte (a sabedoria da sua finitude) faz com que a negação do escravo seja diferente da negação do desejo ou do senhor, pois agora a negação não é pura, mas é uma suprassunção ( aufheben, uma negação que afirma), a negação não é apenas um consumo, mas o desejo é refreado e nisso se torna a complexidade do trabalho em que o desejo não é individual, mas pode passar a ser universal. Com o instinto refreado no trabalho se inicia uma formação social-cultural pelo escravo, pois no trabalho o escravo forma um objeto (transforma a natureza) ao mesmo tempo em que educa a si mesmo (é disciplinado pelo servir), ou seja, ele é produtor e auto-produtor de si. Por isso o produto do trabalho não é mera produção, mas é a exteriorização (HEGEL, 2007, p.151) da sabedoria da consciência escrava onde a sua ação de desejo não é só para si, mas também para o outro. Por isso no produto do trabalho a consciência-de-si reencontra a sua verdade, pois nele haveria a verdade ética do fim em si mesmo, e é apenas nisso que a consciência-de-si pode “chegar à intuição do ser independente" (HEGEL, 2007, p.150).

Tanto o escravo como o senhor estão numa relação de dependência nesse silogismo da dominação, mas é pelo produto do trabalho que pode haver uma intuição de sua independência, por isso a dialética do senhor e escravo chega a uma conclusão apenas no produto do trabalho do escravo. A independência da consciência-de-si ocorre apenas por meio da intuição da independência pelo produto do trabalho. O produto do trabalho é a exteriorização da sabedoria do escravo (medo da morte e desejo refreado), mas ele mesmo esquece essa sabedoria, podendo apenas intuir no produto do trabalho. 
O trabalho é o primeiro momento da efetivação da consciênciade-si, no qual o pensamento realiza uma ação e toma o exterior para colocar um fim (telos) racional e humano. É nesse sentido que "inconscientemente" o escravo se torna senhor do senhor e o senhor escravo do escravo, chegando à inversão daquilo que está mostrado imediatamente no começo dessa relação. Aqui ainda não chegamos à liberdade e nem um reconhecimento recíproco, mas trata-se do que Hegel (HEGEL, 2007, p.151) chamou de uma liberdade no interior da escravidão (HEGEL, 2007, p.151). É necessário encontrar uma solução para acabar com essa unilateralidade e desigualdade no reconhecimento para que o homem se torne senhor de si, ou seja, deve-se chegar à solução do silogismo da dominação chegando ao conceito abstrato do reconhecimento na objetividade (reconhecimento mútuo).

Para Hegel, o conceito de reconhecimento recíproco é a substância ética que deve ser efetivada, pois é nesse reconhecimento que o homem se torna fim em si mesmo. A dialética do senhor e escravo não é uma pré-história ou uma história humana, mas uma categoria da vida histórica ou uma condição da experiência humana. Essa categoria mostra a desigualdade entre o conceito de reconhecimento (reconhecimento mútuo) e a realização desse reconhecimento (reconhecimento desigual). Assim, no devir da consciência e do espírito, deve-se partir de uma desigualdade em que impera um egoísmo para chegar às plenas ética e liberdade, ocorrendo nisso a unidade do conceito (ou sujeito) com o objeto. A consciência deve efetivar essa substância ética não só internamente (como ocorre na Razão), mas em todo o espírito. Essa efetivação da substância ética no espírito pode ter um duplo caminho: um fenomenológico e é lógico e dentro do espírito objetivo. A partir desse último aspecto é possível compreender a efetivação da substância ética no Estado ético que Hegel expõe na sua filosofia do direito, pois a universalidade estatal realizaria um refinamento da particularidade das necessidades em conflito e desigualdade no trabalho dentro da sociedade civil para elevar a uma universalidade substancial, racional e livre, onde todos se reconhecem como cidadãos e por meio dela todos trabalham para satisfazer as suas necessidades e as alheias ao mesmo tempo em que se satisfazem pelo trabalho dos outros. 
Entretanto, apesar desse destaque centrado no homem dentro do reconhecimento, devemos destacar que o reconhecimento, ou melhor, a reconciliação que Hegel tem como principal motor de sua filosofia não é do homem com o homem, mas sim a reconciliação do pensamento com si mesmo em seu ser-outro (natureza). O pensamento para Hegel não é apenas um instrumento ou faculdade humana, mas o pensamento é o sujeito que deve se autodeterminar. O reconhecimento mútuo entre as consciências seria apenas uma condição para uma reconciliação do pensamento com ele mesmo através do homem, reconciliação essa que precisa ainda passar pela religião e filosofia para se completar.

Esse aspecto da filosofia de Hegel será contestado por Marx, através da influencia de Feuerbach, considerando que a ontologia hegeliana seria falsa por partir de um ser somente de maneira abstrata, não tomando então o ser objetivo e verdadeiro da realidade, mas apenas o ser do pensamento abstrato. Essa posição já está presente no jovem Marx (2005) quando contesta a filosofia do direito de Hegel em relação à questão do Estado ético, abrindo uma nova perspectiva da dialética do reconhecimento.

Como destacamos, para Hegel o Estado ético é a efetivação da Idéia ética, por isso o Estado com sua universalidade consegue resolver os conflitos da sociedade civil e da família. Marx nota que em Hegel a relação da família e da sociedade civil é colocada como uma atividade interior da Idéia ética efetivada (Estado ético) fazendo com que o Estado apareça antes de sua própria realização. A sociedade (família e sociedade civil) é entendida por Hegel como esfera conceitual finita do Estado, por isso ela seria passiva e o Estado ativo, sendo assim o verdadeiro sujeito seria apenas a Idéia que se efetiva no Estado ético, logo a solução para os conflitos sociais do homem é algo exterior a ele. Marx não aceitará que o Estado seja o sujeito verdadeiro, mas o verdadeiro sujeito é a esfera finita da família e da sociedade civil. Com essa crítica marxiana à Hegel, nota-se que não seria mais possível conceber o Estado ético como o momento do reconhecimento recíproco, pois o Estado ético seria uma autodeterminação abstrata, e não seria por meio dele que o conflito da dialética do reconhecimento seria resolvido. $O$ Estado não teria a 
verdade da necessidade da sociedade e não seria possível através dele elevar a sociedade a uma vida universal. A elevação da sociedade ao universal seria possível apenas pela própria sociedade, ou melhor, pela própria formação social do homem e pelas necessidades natural-sociais desenvolvidas na dialética do trabalho. Com isso, uma análise sócioeconômica será importante para Marx, pois o ser social será verdadeiro sujeito.

A análise social de Marx terá por base aspectos que ele considerava positivo na filosofia de Hegel, sendo possível afirmar que a autenticidade de Marx está em retornar, sob pressupostos materialistas, às questões tratadas por Hegel na dialética do reconhecimento, ou seja, Marx reabsorve as noções da dialética do reconhecimento dentro do materialismo, formando assim o materialismo dialético.

A antropologia de Marx não negara os fatos naturais, tal como em Hegel. O homem enquanto ser imediato está em dependência e determinado pela natureza, pois sendo um ser natural ele é dependente e limitado do sensível. Tal como Hegel considerava na dialética do desejo, Marx considera que o homem tem uma relação imediata com o seu ser-outro através de um impulso e desejo ilimitado e insaciável (MARX, 2004, p.127).

Por outro lado, ao mesmo tempo, Marx também considera que o homem não é apenas um ser natural que está preso na má infinitude do desejo, mas o homem é um ser sensível universal, ou melhor, o homem é um ser genérico. Mas em que consiste em ser genérico para Marx? O autor considera que o homem se torna universal quando ele não se encontra apenas imediatamente em contato com a natureza, mas sim, tal como ocorre com a passagem da dialética do desejo à dialética do reconhecimento em Hegel, quando o homem se relaciona com a natureza através da sociedade. $\mathrm{O}$ homem é universal na medida em que está em elo com outro homem, por isso a essência humana é o homem em sociedade, em relação social (MARX, 2004, p.127). E a essência dessa relação social consiste naquele agir do trabalho, no qual a ação do desejo particular passa a ser ação universal do trabalho. Assim, o homem só se torna universal na medida em que ele está em relação consigo mesmo e 
com a natureza pela mediação do trabalho (MARX, 2004, p.84-85), pois o trabalho é social por si mesmo, dado que nele a ação não é apenas para si, mas também para o outro. É verdade que Marx considera que a satisfação das necessidades humanas começa pelo seu meio de vida dado pela natureza, mas o homem não se limita a esse meio de vida, o homem transcende esse limite na medida em que ele produz o seu próprio meio de vida e suas necessidades, que são transformadas no processo de produção em necessidades natural-humanas. Essa posição de Marx ocorre por concordar e elogiar a descoberta de Hegel sobre a essência do trabalho (MARX, 2004, p.123), sendo isso uma base para mostrar como o homem é um ser genérico e se diferencia dos outros seres naturais.

Entretanto, para Marx, tal como também para Hegel, o trabalho não se efetiva numa relação mútua de igualdade, mas, pelo contrário, o trabalho vem justamente de uma desigualdade e de uma relação unilateral de domínio. Isso porque, como salientamos acima, o homem continua sendo parte da natureza, então no desenvolvimento da história humana o trabalho é estranhado ${ }^{3}$, e isso ocorre principalmente pelo fato do trabalho se configurar historicamente de modo que o ato do trabalho e o produto do trabalho são uma forma de dominação e não uma maneira de elevar as suas capacidades universais à sua potência enquanto ser genérico. Nesse sentido, Marx considera que historicamente a dialética do trabalho tem em si o silogismo da dominação, tal como é descrita por Hegel, mas esse silogismo da dominação não é uma categoria do trabalho, tal como era em Hegel, mas uma condição histórica do trabalho estranhado e não do trabalho em geral. $\mathrm{O}$ homem não se relaciona em sua potência universal, logo ele não tem um verdadeiro domínio sobre as coisas que produz. Pelo contrário, as coisas se tornam meio de dominação entre os homens, e por isso um poder acima dos homens. Assim, a dependência e dominação, que estavam dentro do silogismo da dominação em Hegel, reaparecem em Marx na relação que o homem tem com os seus objetos,

\footnotetext{
${ }^{3}$ Seguimos aqui a tradução de Jesus Ranieri de Entäußerung por estranhamento e não alienação. Para a justificativa dessa escolha consultar MARX, 2004, p. 15-16.
}

\begin{tabular}{l|l}
\hline 70 & Da dialética do reconhecimento em Hegel à dialética do trabalho...
\end{tabular} 
ou seja, com os seus objetos produzidos e consumidos dentro do estranhamento do trabalho. No capitalismo, por exemplo, a relação humana por meio da propriedade privada não corresponde ao desenvolvimento de necessidade humana e a satisfação dessas necessidades, não visa à riqueza total do homem enquanto ser genérico, mas pelo contrário, essa relação ocorre, tal como na dialética do senhor e escravo, de uma maneira onde "cada um procura criar uma força essencial estranha sobre o outro, para aí encontrar a satisfação da sua própria necessidade interesseira" (MARX, 1993, p.129). O homem visa dominar um outro homem por meio da sua produção, por isso ele não consegue ter uma relação humana entre si e com os seus objetos.

Até agora é notável as convergências entre Hegel e Marx, mas é necessário também destacar as divergências entre os autores, que os levam a terem outra concepção filosófica. Essa divergência é visível no apontamento que Marx faz de uma dupla ilusão de Hegel (MARX, 2004, p.129), que resumidamente passa-se no seguinte: 1- Hegel considera a consciência-de-si como um ser pensante que está no seu ser-outro (sensível), ou seja, quando Hegel considera o homem como consciência ou consciência-de-si, ele considera o homem de maneira abstrata, como um ser pensante dentro do sensível, a essência do homem não era o próprio homem (em sua auto-produção), mas é o pensamento que se auto-produz a si mesmo; 2- como conseqüência, a objetivação da consciência-de-si através do trabalho não será a objetivação estranhada de si mesmo (do próprio homem), mas seria a objetivação de sua essência enquanto pensamento. Ora, para Marx e Hegel, o trabalho é uma exteriorização do homem, mas para cada um dos autores há uma significação diferente dessa exteriorização. Para Hegel, no produto do trabalho há uma exteriorização pela qual é possível intuir o seu ser independente. Para Marx, essa exteriorização de um ser independente tem um caráter de estranhamento, pois o sujeito real (o homem) fica dependente do ser independente exteriorizado (produto do trabalho). Hegel, por não tomar o homem como sujeito real, não nota o estranhamento nessa exteriorização, assim na exteriorização do trabalho o homem encontra o que é a sua essência ética como independente. Já 
em Marx a independência do homem está em ser auto-produtivo dentro da relação sensível, pois o homem real é o sujeito ativo, logo o produto do trabalho estranhado é sim para ele independente do homem e do sensível, mas nessa independência o homem não pode e não consegue intuir a sua independência, mas apenas pode sofrer dessa independência do produto de seu trabalho a mais cruel dependência: estranhamento do trabalho.

Na dialética do senhor e escravo, Hegel não coloca como solução uma mudança na relação do trabalho, ele mantém essa relação de domínio como um princípio e condição para o trabalho na história humana. Com isso, o silogismo da dominação dentro da dialética do trabalho de Hegel é colocado como uma categoria fora da história e sem possibilidade de uma modificação da relação de trabalho, ou seja, sem possibilidade de reconhecimento mútuo dentro da própria dialética do trabalho. Conseqüentemente, o suprassumir (aufheben) de Hegel não é um suprassumir das contrações da condição da existência humana, mas do pensamento; "este suprassumir é um suprassumir do ser pensado, portanto, a propriedade privada, pensada suprassume-se no pensamento da moral" (MARX, 2004, p.131). O suprassumir de Hegel é sempre um suprassumir do pensar ético, e não efetivo. Então, no suprassumir não se trata das contradições do homem (estranhamento do trabalho), mas sim de um suprassumir das contradições do pensamento abstrato. Em Marx o suprassumir sensível será da relação de desigualdade e unilateralidade dentro da produção efetiva, trata-se da emancipação humana no qual o homem e a natureza são sujeitos reais e não mais o pensamento. Ocorre então também em Marx a passagem do reconhecimento unilateral e desigual para o reconhecimento mútuo e igual, entretanto não mais mediado por um pensamento abstrato efetivado pelo Estado ético, mas pela própria relação efetiva do homem com a natureza através do trabalho.

Com a emancipação humana, ocorre uma completa mudança na relação do trabalho e na relação do homem com essa produção. Essa solução na qual se modifica o próprio modo de produzir do homem é recusada por Hegel que considera como permanente a relação de 
desigualdade dentro do trabalho, sendo apenas por um Estado ético a possibilidade de mediar e regular essa relação de trabalho. Para Marx, a emancipação humana completa visa uma mudança na relação de trabalho e a relação do homem com o produto desse trabalho, visa uma relação de poder no qual o homem não realiza uma objetivação para a dominação de um outro homem, mas uma objetivação para reafirmar a potência humana universal. Dessa maneira, o homem retorna a sua essência universal, ou seja, o homem realiza uma reapropriação do seu ser genérico. Esse suprassumir é a emancipação que leva o homem ao comunismo, e com isso o homem tem a apropriação efetiva da sua essência humana enquanto auto-produtor de si, enquanto ser independente (MARX, 2004, p.105).

Em certa medida está presente na emancipação humana o reconhecimento mútuo de Hegel, pois Marx visa uma relação recíproca entre os homens, realizando nisso a satisfação das necessidades de todos os homens, mas em Marx, diferente de Hegel, isso ocorre dentro da relação do trabalho, no qual o homem produziria ao mesmo tempo para si e para todo o gênero humano. Nos Cadernos de Paris há uma passagem que Marx supõe essa produção emancipada. Nessa passagem é bem notável o reconhecimento recíproco dentro dessa produção (MARX, 1980, p.155156).

Enfim, nota-se que, em certa medida, a meta final tanto de Marx como de Hegel é a mesma: uma relação recíproca no qual o homem satisfaz todas as suas necessidades dentro da liberdade; mas cada um com diferentes significações e de diferentes maneiras para alcançá-la. A dialética do reconhecimento é acolhida por Marx principalmente pelo fato de o autor destacar um aspecto muito importante dessa dialética: a essência humana sendo tomada como auto-produção de si, na medida em que o homem tem o seu meio de vida produzido pelo trabalho. Nesse sentido, a essência humana não será mais um objeto sensível universal que o homem intui, tal como era no materialismo de Feuerbach, mas será sim a atividade humana enquanto ser social, ou seja, será práxis que se efetiva pelo trabalho. Ao mesmo tempo, Marx reconhece e critica, por já tomar para si as críticas materialistas, a maneira abstrata com a 
qual o idealismo de Hegel toma a atividade humana ainda distante da atividade real. Mas pelo fato de Marx considerar o aspecto ativo desenvolvido pelo idealismo de Hegel ele empregará a dialética do reconhecimento interligada de maneira materialista com os importantes conceitos de ser genérico (essência humana), estranhamento do trabalho e emancipação humana.

\section{Referências Bibliograficas}

HEGEL, Georg Wilhelm Friedrich. Fenomenologia do espírito, $4^{\mathrm{a}}$ Edição, Rio de Janeiro: Editora Vozes, 2007.

HONNETH, Axel. Luta por Reconhecimento: a gramática moral dos conflitos sociais. São Paulo: Ed. 34, 2003

KOJÉVE, Alexandre. Introdução à leitura de Hegel. Rio de Janeiro: Contraponto/EDUERJ, 2002.

MARX, Karl. Critica da filosofia do direito de Hegel. São Paulo: Boitempo editorial, 2005.

. Cuardernos de Paris. Notas de lecturas de 1844. 2. ed. México: Era, 1980.

Manuscritos econômico-filosóficos. São Paulo: Boitempo editorial, 2004.

74 Da dialética do reconhecimento em Hegel à dialética do trabalho... 
Manuscritos econômico-filosófico de 1844. Lisboa: Avante!, 1993.

MÉSZÁROS, István. Filosofia, ideologia e ciência social: ensaios de negação e afirmação. São Paulo: Editora Ensaio.

VÁZQUEZ, Adolfo Sánchez. Economia y humanismo. In MARX, K. Cuadernos de Paris: notas de lectura de 1844. 2. ed. México: Era, p. 1397, 1980. 
